\title{
On the Relationship between Estimate and Its $t$ Value
}

\author{
Yuji Matsuoka1, Shigeyuki Hamori2 \\ ${ }^{1}$ Graduate School of Economics, Kobe University, Kobe, Japan \\ ${ }^{2}$ Faculty of Economics, Kobe University, Kobe, Japan \\ Email: hamori@econ.kobe-u.ac.jp
}

Received 1 December 2014; accepted 14 December 2014; published 13 January 2015

Copyright (C) 2015 by authors and Scientific Research Publishing Inc.

This work is licensed under the Creative Commons Attribution International License (CC BY). http://creativecommons.org/licenses/by/4.0/

(c) (i) Open Access

\section{Abstract}

It is generally believed that the signs of the estimated coefficient and its $t$ value should be the same. This paper, however, shows that there may be an inconsistency in the signs of the estimated coefficient and its $t$ value when we use the group mean dynamic OLS estimator developed by Pedroni (2001).

\section{Keywords}

$t$ Value, Group Mean Dynamic OLS Estimator, Panel Data

\section{Introduction}

This paper shows the possibility of inconsistency in the signs of the group mean dynamic OLS estimator and its $t$ value. According to basic econometrics and statistics, the $t$ value is calculated by dividing the estimated coefficient by its standard error. Because the standard error is always positive, the sign of the $t$ value becomes identical to the sign of the estimated coefficient [1] [2].

Pedroni [3] developed the group mean dynamic OLS estimator - a useful technique to obtain an estimator for a dynamic heterogeneous panel model. However, because this estimator is calculated by summing the estimation result of every cross section, there is a possibility of inconsistency in the signs. We provide a very simple example of this phenomenon.

The remainder of this paper is as follows: Section 2 provides the model; Section 3 shows the simulation; Section 4 concludes.

\section{Model}

We consider the estimation of the following model by using dynamic OLS. 


$$
y_{i t}=\beta_{0 i}+\beta_{1 i} x_{i t}+\sum_{m=-M}^{M} \delta_{m} \Delta x_{i t-m}+u_{i t}, \quad i=1, \cdots, N, \quad t=1, \cdots, T
$$

where $y_{i t}$ is the dependent variable, $x_{i t}$ is the independent variable, and $u_{i t}$ is the error term. To obtain the group mean dynamic OLS estimator, we separately estimate this equation using every cross section. Then, we calculate the estimator with each estimated coefficient and $t$ value in the following manner:

$$
\begin{gathered}
\hat{\beta}_{1}=\frac{1}{N} \sum_{i=1}^{N} \hat{\beta}_{1 i}, \\
t\left(\hat{\beta}_{1}\right)=\frac{1}{N^{\frac{1}{2}}} \sum_{i=1}^{N} t\left(\hat{\beta}_{1 i}\right) .
\end{gathered}
$$

\section{Simulation}

\subsection{Simulation Design}

We show the possibility of inconsistency using a simulation. For simplicity, we assume that $N$ and $T$ equal 2 and 1000, respectively. Furthermore, we drop the lag and lead terms. The model is rewritten as follows:

$$
\begin{gathered}
y_{1 t}=\beta_{01}+\beta_{11} x_{1 t}+u_{1 t}, \quad t=1, \cdots, T \\
y_{2 t}=\beta_{02}+\beta_{12} x_{2 t}+u_{2 t}, \quad t=1, \cdots, T \\
\hat{\beta}_{1}=\frac{1}{2} \sum_{i=1}^{2} \hat{\beta}_{1 i} \\
t\left(\hat{\beta}_{1}\right)=\frac{1}{2^{\frac{1}{2}}} \sum_{i=1}^{2} t\left(\hat{\beta}_{1 i}\right)
\end{gathered}
$$

The simulation strategy is as follows. First, we provide the values of $\beta_{01}, \beta_{02}, \beta_{11}$ and $\beta_{12}$ as Case 1:

$$
\left(\beta_{01}, \beta_{02}, \beta_{11}, \beta_{12}\right)=(1,1,2,2)
$$

Case 2:

$$
\left(\beta_{01}, \beta_{02}, \beta_{11}, \beta_{12}\right)=(1,1,-2,-2)
$$

Case 3:

$$
\left(\beta_{01}, \beta_{02}, \beta_{11}, \beta_{12}\right)=(1,1,2,-2) .
$$

Second, we randomly generate the values of $x_{1 t}$ and $x_{2 t}$ and $u_{1 t}$ and $u_{2 t}$ using standard normal distributions. Then, we calculate the values of $y_{1 t}$ and $y_{2 t}$. Third, we estimate the above equation and calculate the estimator by using the generated data. This simulation is performed 10,000 times using STATA.

\subsection{Simulation Results}

Case 1 and Case 2:

In this case, we expect that both cross sections take identical signs. Thus, we do not need to be concerned with the inconsistency. The result also shows consistency: every 10,000 samples take the same signs in the group mean dynamic OLS estimator and its t value.

Case 3:

In this case, the estimation of each cross section is expected to take opposite signs. Then it might be possible that inconsistency in the signs of the group mean dynamic OLS estimator and its $t$ value occurs. Table 1 presents the result. 
Table 1. Results of case 3 .

\begin{tabular}{cccc}
\hline & Coefficient & $t$ Value & Sample Size \\
\hline \multirow{2}{*}{ Consistent } & Positive & Positive & 2576 \\
& Negative & Negative & 2453 \\
\multirow{2}{*}{ inconsistent } & Positive & Negative & 2488 \\
& Negative & Positive & 2483 \\
\hline
\end{tabular}

\section{Conclusion}

In this paper, we show that there may be an inconsistency in the signs of the estimated coefficient and its $t$ value when we use the group mean dynamic OLS estimator developed by Pedroni (2001).

\section{Acknowledgements}

We are grateful to three anonymous referees for their helpful comments and suggestions.

\section{References}

[1] Stock, J.S. and Watson, M.W. (2011) Introduction to Econometrics. 3rd Edition, Addison-Wesley, Boston.

[2] Wooldridge, J.M. (2013) Introductory Econometrics: A Modern Approach. 5th Edition, South-Western Pub, Mason.

[3] Pedroni, P. (2001) Purchasing Power Parity Tests in Cointegrated Panels. Review of Economics and Statistics, 83, 727731. http://dx.doi.org/10.1162/003465301753237803 
Scientific Research Publishing (SCIRP) is one of the largest Open Access journal publishers. It is currently publishing more than 200 open access, online, peer-reviewed journals covering a wide range of academic disciplines. SCIRP serves the worldwide academic communities and contributes to the progress and application of science with its publication.

Other selected journals from SCIRP are listed as below. Submit your manuscript to us via either submit@scirp.org or Online Submission Portal.
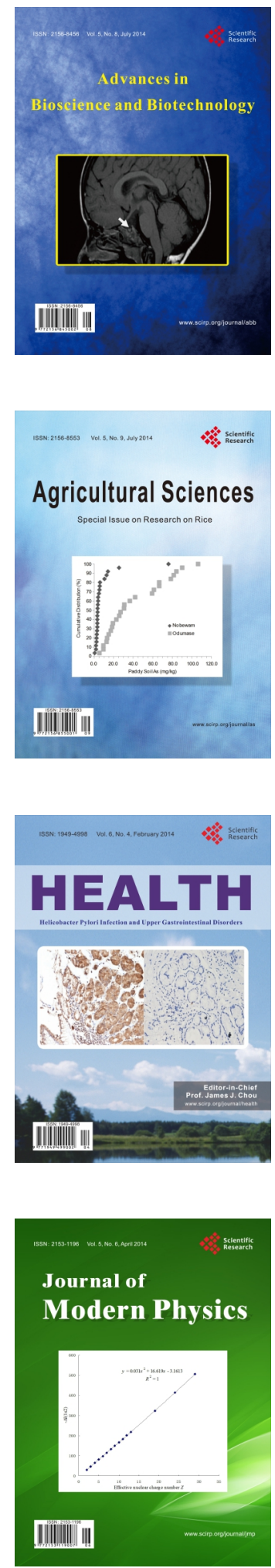
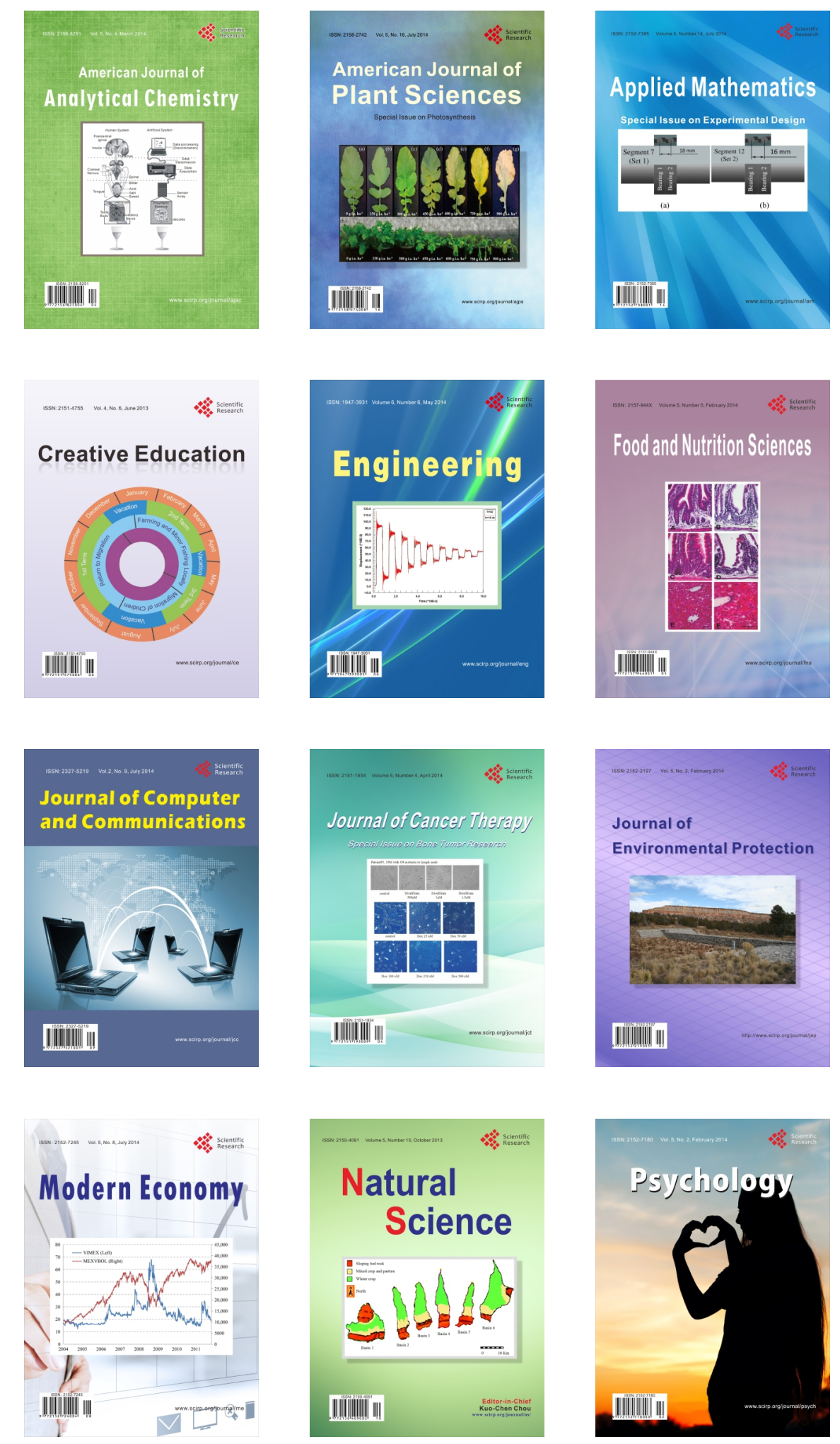